\title{
INTERNACIONALIZAÇÃO DA LÍNGUA PORTUGUESA: ASSIMETRIAS, HETEROGENEIDADE E PODER
}

\author{
INTERNATIONALIZATION OF THE PORTUGUESE LANGUAGE: \\ ASYMMETRIES, HETEROGENEITY AND POWER
}

\author{
Cristine Gorski Severo ${ }^{1}$, Charlott Eloize Leviski ${ }^{2}$
}

\begin{abstract}
RESUMO: Este artigo aborda as políticas, discursos e práticas envolvendo a internacionalização da língua portuguesa no mundo a partir de uma perspectiva crítica. Para tanto, inicialmente, apresentamos um panorama sobre a situação linguística de alguns países cuja língua oficial é a portuguesa - Angola, Moçambique, Timor Leste, Cabo Verde e Guiné-Bissau -, apontando para a heterogeneidade e as assimetrias que envolvem as línguas e seus falantes nesses contextos. Em seguida, discorremos sobre algumas políticas institucionalizadas - CPLP e governos brasileiro e português - envolvendo a difusão e normatização do português. Por fim, apontamos para as relações de poder que envolvem as práticas e discursos de internacionalização da língua portuguesa que, de forma geral, têm priorizado alguns em detrimentos de outros, ressonando uma matriz lusófona colonial.
\end{abstract}

PALAVRAS-CHAVE: português no mundo; internacionalização; assimetria; CPLP; África.

\begin{abstract}
This article discusses policies, discourses and practices involving the internationalization of the Portuguese language from a critical perspective. To do so, initially, we present an overview of the linguistic situation of some countries whose official language is Portuguese - Angola, Mozambique, East Timor, Cape Verde and Guinea Bissau - pointing to the heterogeneity and the asymmetries involving languages and their speakers in these contexts. Next, we discuss some institutionalized policies - based on CPLP and Brazilian and Portuguese governments - involving the diffusion and normalization of Portuguese. Finally, we point to the power relations that involve the practices and discourses of internationalization of the Portuguese language that, in general, have prioritized some to the detriment of others, echoing a colonial Lusophone framework.
\end{abstract}

KEY-WORDS: Portuguese; internationalization; asymmetries; CPLP; Africa.

\section{Introdução}

\footnotetext{
${ }^{1}$ Doutora em Teoria e Análise Linguística (UFSC, 2007) e em Ciências Humanas (UFSC, 2018).

${ }^{2}$ Doutoranda em Linguística (UFSC).
} 
Neste artigo, abordamos os discursos de internacionalização da língua portuguesa, a partir de uma perspectiva crítica. Propomos que o processo de internacionalização da língua portuguesa está em diálogo com a ideia - colonial e contemporânea - de lusofonia, entendida como um dispositivo (Foucault, 2015) que integra elementos linguísticos, culturais, identitários e econômicos com efeitos simbólicos e políticos específicos no universo de circulação e oficialização da língua portuguesa. Propomos que a lusofonia contemporânea, empenhada na propagação e celebração acrítica da língua portuguesa no mundo, ressoa práticas e discursos coloniais que utilizaram a língua portuguesa como instrumento de dominação através da cristianização, da escolarização, da política de assimilação e da escravização (Severo e Makoni, 2015). A visão crítica adotada por nós implica questionar quem ganha com as políticas de internacionalização da língua portuguesa em contextos para além do brasileiro e português, a exemplo dos países que são membros da Comunidade dos Países de Língua Portuguesa (CPLP): Portugal, Brasil, Angola, Moçambique, Guiné-Bissau, Guiné Equatorial, Cabo Verde, Timor Leste e São Tomé e Príncipe.

Consideramos que a complexidade linguística e cultural que caracteriza os diferentes países cuja língua oficial é a portuguesa deve ser levada em conta quando analisamos o papel da internacionalização da língua portuguesa, com fins de se evitar a reiteração de discursos brasileiros ou portugueses como definidores de políticas com alcance transnacional. Além disso, compreendemos que os conceitos de língua e de educação devem dialogar com as realidades locais, considerando os valores e representações de diferentes etnias e culturas que integram os países "lusófonos". Assim, neste artigo buscamos uma atitude cautelosa, atentando para uma memória colonial que ainda ressoa nas disparidades linguísticas e no acesso à justiça social em diferentes países falantes de língua portuguesa. Ressaltamos que o projeto de internacionalização, contudo, não é novo, mas pode nos remeter às práticas coloniais centradas na coroa portuguesa: "durante o século XVI, na medida em que o colonizador português estabelecia sua presença em cidades portuárias da Ásia e da África Oriental, a língua portuguesa era cada vez mais adotada como um meio de comunicação internacional, embora de forma simplificada" (Disney, p. 2007, p. 299). Embora nosso

\footnotetext{
3 “ [...] during the course of the sixteenth century, as the Portuguese stablished their presence throughout the port cities of Asia and East Africa, Portuguese itself was increasingly adopted as an international medium of communication, albeit in a simplified form." Traduções de nossa responsabilidade.
} 
enfoque não sejam as políticas coloniais, atentamos para a importância dessa história na definição do lugar simbólico atribuído à língua portuguesa.

A seguir, apresentamos um panorama linguístico da situação do português em alguns países que são membros da CPLP, com enfoque no contexto africano. Tendo em mente essa diversidade linguística e cultural, na sequência discorremos sobre os projetos levados a cabo pela CPLP, a exemplo do Instituto Internacional da Língua Portuguesa e das políticas de normatização dessa língua portuguesa internacional. Enfocamos, também, o projeto de internacionalização da língua portuguesa como integrante das agendas políticas de Portugal e do Brasil, países majoritariamente falantes de língua portuguesa como língua materna. Por fim, reafirmamos a existência de uma tensão e de assimetrias entre políticas de internacionalização da língua e a realidade local de contextos africanos.

\section{As línguas portuguesas no mundo: heterogeneidade, assimetrias e poder}

Para ilustrar a maneira como a língua portuguesa assume papeis diferentes em diferentes contextos, mencionamos algumas estatísticas governamentais, mesmo sabendo que tais estatísticas são reféns de metodologias nem sempre detalhadas e atentas ao funcionamento complexo das línguas (Fardon e Furniss, 1993). Conforme o Censo angolano de 2014, a língua quimbundu é falada por $8 \%$ da população angolana, juntamente com o kikongo; dentre as línguas angolanas mais faladas está o umbundu, totalizando $23 \%$ da população. Em Angola, há uma forte discrepância distribuída geopoliticamente entre falantes de português e das línguas nacionais - enquanto o espaço urbano totaliza em torno de $70 \%$ de falantes de português, nas áreas rurais $49 \%$ não sabe falar português. Tal discrepância tem mobilizado uma série de iniciativas e pesquisas sobre o papel da educação bilíngue - língua portuguesa e língua nacional - na formação dos alunos (Bernardo, 2018; Severo, 2014). Já em Moçambique, o censo de 2007 mostra que $10 \%$ da população fala português e $85 \%$ domina língua bantu. Notemos que tal situação linguística diferenciada - entre Angola, Moçambique e Brasil, por exemplo - é fruto de diferentes percursos coloniais e pós-independência que, a despeito de um projeto lusófono colonizador, manteve suas singularidades locais.

Ainda na esteira dos discursos censitários como ilustrativos das assimetrias linguísticas envolvendo a língua portuguesa no mundo, em Timor Leste, em 2010, a taxa de letramento em língua portuguesa entre pessoas de 15 e 24 anos era de $39 \%$, contra $77 \%$ em tétum e $55 \%$ 
em indonésio (Dias, 2015). Já em Guiné-Bissau, o censo de 2009 mostra que a língua crioula seria falada por mais de $90 \%$ da população, enquanto a língua portuguesa seria falada por cerca de 10\%; além disso, em Bissau, 46\% dos residentes de áreas urbanas falariam português contra $14 \%$ das áreas rurais. Sobre a escolarização neste país, 43\% da população não frequentou a escola. Além disso, quando indagados pelo Censo sobre se consideravam a sua língua materna como sendo a principal falada em Guiné-Bissau, todas as etnias tendiam a reconhecer a prioridade de sua língua, a exemplo dos Fulas (86,9\%), Felupes (85,8\%), Balantas $(84,7 \%)$ e Manjacos (83,1\%). Em face dessa assimetria linguística, valorativa e escolar, o relatório estatístico de Guiné-Bissau atesta que "A língua foi um dos primeiros elementos de dominação colonial e constitui um meio de dominação ou de afirmação de identidade cultural" (Guiné-Bissau, III RGPH, 2009, p. 32).

Em Cabo Verde, o artigo nono da Constituição (1992) postula que a língua oficial é o português, sendo que cabe ao Estado promover "condições para a oficialização da língua materna cabo-verdiana, em paridade com a língua portuguesa". O censo de 2015 deste país mostra que $72 \%$ da população acima de 12 anos se comunica em língua portuguesa, sendo que dentre tais falantes, $80 \%$ seria residente da área urbana e 54\% da área rural. Além disso, a população mais idosa falaria menos português do que a população mais jovem, o que sinaliza para um cenário futuro de ampla expansão da língua portuguesa neste país (Cabo Verde, INE, 2015). Essa disparidade etária entre falantes de línguas africanas e português também se evidencia em Angola (Bernardo, 2018), o que revela o papel que os mais velhos deixaram de ocupar na formação linguística e cultural - seguindo uma tradição oral - dos mais jovens. Esse é um exemplo da maneira como um dado modelo de escolarização tem operado na definição do que conta como "educação" e formação moral dos sujeitos.

Compreendemos que as sociedades multilíngues de tradição oral e que passaram pelo processo colonial tendem a ser prejudicadas no contexto educacional, pois esses países acabam reproduzindo iniciativas educacionais centradas na alfabetização, priorizando as línguas com registro escrito. O papel da escrita na configuração de uma representação escolar sobre a língua muitas vezes é reforçado por discursos em prol da "alfabetização" tomada como bandeira política e signo de desenvolvimento social e econômico. Muitas vezes, tais discursos raramente contemplam o papel da oralidade e da tradição local na configuração do que conta como língua, a exemplo do Índice de Desenvolvimento Humano (IDH), uma medida internacional usada para a avaliar o desenvolvimento humano a partir de três 
elementos interligados: saúde, educação e renda. O quesito educação é medido pelos seguintes fatores:

i) média de anos de educação de adultos, que é o número médio de anos de educação recebidos durante a vida por pessoas a partir de 25 anos; e ii) a expectativa de anos de escolaridade para crianças na idade de iniciar a vida escolar, que é o número total de anos de escolaridade que um criança na idade de iniciar a vida escolar pode esperar receber se os padrões prevalecentes de taxas de matrículas específicas por idade permanecerem os mesmos durante a vida da criança;

Entendemos que os conceitos de escola e de escolarização nem sempre dialogam com as concepções locais do que conta como educação e formação moral e intelectual. No caso africano, as teorias de letramento se tornaram os moldes para definir o que conta como língua (Makoni e Meinhof, 2006), criando assimetrias entre grupos e pessoas em torno do maior ou menor acesso à língua letrada e escolarizada; assim, a tradição oral - e a relação geracional passa a ser definida a partir das representações de letramento e de escolarização. Se a educação e o ensino de línguas desempenham um papel relevante nas políticas públicas nacionais e internacionais, acreditamos que ela deve levar em conta as demandas e práticas locais, especialmente em contextos linguisticamente complexos:

Para o ensino de línguas nativas ter resultado, será necessário minimizar as disjunções não somente entre o "meio de instrução" e as práticas linguísticas em casa, mas principalmente reduzir as diferenças entre a pedagogia conforme a praticada nas escolas e a pedagogia conforme compreendida nas sociedades africanas "tradicionais" (Makoni e Meinhof, 2006, p. 200).

Além disso, sabemos que os censos e outras medidas de levantamento de dados integram uma política estatal que, muitas vezes, atua na contramão das práticas linguísticas e culturais plurais, especialmente quando o lema "uma nação, uma língua" é usado para reiterar sentimentos de unificação e de homogeneização. O levantamento linguístico feito pelos censos tende a reforçar conceitos estáticos e homogêneos de língua, em que cada língua recebe um nome e é fragmentada em termos de leitura $v s$. oralidade, escrita $v s$. fala, entre outras diferenciações. Diante disso, compreendemos que em contextos multilíngues, "não há nenhuma resposta clara para a questão relativa a qual língua os enunciados pertencem”

\footnotetext{
${ }^{4}$ Informações acessadas na página do Programa das Nações Unidas para o Desenvolvimento/Brasil, em http://www.br.undp.org/content/brazil/pt/home/idh0/conceitos/o-que-e-o-idh.html. Acesso em: 06 mar. 2019.
} 
(Makoni e Meinhof, 2006, p. 203), isso porque a heteroglossia e a hibridização linguística e cultural vai na contramão de uma política classificatória que caracteriza os censos. Nesses contextos, a definição das fronteiras linguísticas se torna complicada, uma vez que os sujeitos misturam seus repertórios conforme as práticas sociais. Estamos, portanto, diante de contextos comunicativos multilíngues complexos (Garcia, 2009), internamente dialogizados (Bakhtin,1988), multimodais e multissemióticos (Pennycook, 2014; Blommaert, 2010). Diante dessa complexidade, indagamos o que conta como língua portuguesa, quem define os limites dessa língua e o que significaria expandir e internacionalizar a "língua portuguesa".

A língua portuguesa no cenário dos discursos e práticas de internacionalização inscreve tensionamentos que envolve a relação entre as políticas transnacionais e as políticas estatais, produzindo, por exemplo, o português brasileiro, o português moçambicano, o português angolano, e assim por diante. O português moçambicano (PM), por exemplo, tem sido estudado e descrito sob diferentes enfoques: condições sócio-históricas de formação do PM (Timbane, 2017; Gonçalves, 2012); estudos contrativos do PM em relação ao PB e PE; influência das Línguas Bantu moçambicanas no PM (Sitoe e Nhamuende, 2002; Ngunga, 2012; Balsalobre, 2017); entre outros. Tais pesquisas servem de suporte para a legitimação do português moçambicano nas escolas, intensificada pela produção de instrumentos linguísticos e material didático nessa língua. No contexto angolano, investigadores e professores também têm se dedicado à descrição e análise do português angolano (PA) em termos de suas especificidades linguísticas e históricas, e da implicação do português falado e escrito no processo de ensino e aprendizagem da norma da língua (Bernardo, 2017; Nzau, 2011; Mingas, 2007; Miguel, 2014, Adriano, 2015).

Esses exemplos nos fazem refletir sobre os perigos de uma celebração acrítica de políticas educacionais de internacionalização da língua portuguesa, especialmente quando estamos diante de sujeitos residentes de países de língua portuguesa como oficial e que não são falantes dessa língua. As políticas de internacionalização parecem sinalizar para a importância de políticas educacionais bilíngues ou translíngues (Garcia e Wei, 2014). O que parece estar em jogo, no cenário de internacionalização e de transnacionalismos, é um questionamento dos limites que definem não apenas as nações, mas as próprias línguas. Afinal, quem define o que conta como "língua portuguesa" em cenários geopolíticos, culturais e históricos multilíngues tão diferenciados e singulares? Assumimos, assim, que a língua portuguesa - nos discursos e práticas de internacionalização - opera como um signo político e econômico, que favorece 
alguns e desfavorece outros. A seguir abordaremos esse tema a partir de uma análise sobre o papel da CPLP e dos discursos nacionais do Brasil e Portugal sobre a língua portuguesa.

\section{Políticas contemporâneas de expansão e normatização do português no mundo}

Nesta seção, apresentamos e comentamos uma série de exemplos que ilustram a relação entre políticas de internacionalização da língua portuguesa e a ideia de um projeto lusófono contemporâneo, o que significa considerar as relações de poder, os interesses econômicos e os efeitos simbólicos implicados das políticas. Enfocamos as políticas institucionais centradas na CPLP e nos governos brasileiro e Portugal. Compreendemos que as instituições desempenham um papel relevante na construção de um imaginário de legitimidade em torno da expansão da língua portuguesa.

Um dos primeiros aspectos que vamos discutir corresponde à criação de instituições contemporâneas encarregadas de difundir a língua portuguesa. A tendência homogeneizante verificada na criação de blocos político-econômicos supranacionais, de instituições políticas internacionais e de agências multilaterais pode ser interpretada como uma das "dimensões políticas da globalização" (Santos, 2002, p. 43). Isso sinaliza para a emergência de um governo global ou global governance (Santos, 2002), um fenômeno em que a criação de blocos supranacionais - com base em princípios da racionalidade coletiva, da liberdade e da igualdade - promove a amplitude e o poder da "institucionalidade transnacional" (Santos, 2002, p. 44).

Nesta esteira, a Comunidade dos Países de Língua Portuguesa (CPLP) foi criada em 1996 a fim de reunir os países em que o português é língua oficial. O acordo político-diplomático está atualmente firmando entre Angola, Brasil, Cabo Verde, Guiné-Bissau, Moçambique, Portugal, São Tomé e Príncipe, Timor-Leste e, mais recentemente em 2014, Guiné Equatorial (CPLP, 2018). Tal comunidade tem operado na construção de um imaginário lusófono e homogêneo da língua portuguesa. Em se tratando de uma comunidade política, essa confere uma nova função transnacional de cooperação entre os países de língua portuguesa, porque está pautada nos princípios de solidariedade e reconciliação (Marchueta, 2003). Conforme a Declaração constitutiva da CPLP, os principais objetivos são: 
- Consolidar a realidade cultural nacional e plurinacional que confere identidade própria aos Países de Língua Portuguesa, reflectindo o relacionamento especial existente entre eles e a experiência acumulada em anos de profícua concertação e cooperação;

- Encarecer a progressiva afirmação internacional do conjunto dos Países de Língua Portuguesa que constituem um espaço geograficamente descontínuo, mas identificado pelo idioma comum;

- Reiterar, nesta ocasião de tão alto significado para o futuro colectivo dos seus Países, o compromisso de reforçar os laços de solidariedade e de cooperação que os unem, conjugando iniciativas para a promoção do desenvolvimento económico e social dos seus Povos e para a afirmação e divulgação cada vez maiores da Língua Portuguesa. (CPLP, 1996, p. 1).

Em 2005, o Instituto Internacional da Língua Portuguesa - IILP, foi anexado à CPLP com o papel de conduzir os principais projetos de materialização e difusão da língua portuguesa. $O$ ato constitutivo do IILP se deu em 1989, na cidade brasileira de São Luís do Maranhão, durante o governo de José Sarney. O tratado foi assinado pelos presidentes dos PALOP, que correspondiam na época a Angola, Cabo Verde, Guiné-Bissau, Moçambique e São Tomé e Príncipe, além do Presidente de Portugal e do Brasil (BRAGA, 1999). Nos últimos anos, a iniciativa do IILP consiste em solidificar um aparato teórico-metodológico no ensino de português como língua estrangeira, uma relação de saber-poder (Foucault, 2015) que constrói seu objeto do português, tomado como língua estrangeira.

Dentre as principais ações conduzidas pelo IILP, destacamos a criação de um instrumento de normatização da escrita da língua portuguesa por meio do Vocabulário Ortográfico Comum VOC - e do desenvolvimento de vocabulários nacionais. Isso possibilita unir as bases léxico-gramaticais do português a fim de criar um vocabulário lexical comum. Trata-se de uma tentativa de criar um 'recurso oficial' de referência para a escrita da língua portuguesa, em que as diferenças linguísticas faladas nos estados-membros são tratadas como variedades do português (Ferreira; Correia; Almeida, 2017). A validação política ocorreu em julho de 2014 por parte dos estados-membros da CPLP, com objetivo de unir em uma única plataforma o acesso aos recursos oficias comuns para aplicação das regras ortográficas (IILP, 2014). O lançamento do VOC ocorreu em 12 de maio de 2017, na sede do IILP, em Cabo Verde (IILP, 2017).

A unificação lexical reforça o papel de língua pluricêntrica atribuída ao português (Baxter, 1992; Silva, Torres, Gonçalvez, 2011; Batoréo, Casadinho, 2009; Batoréo, Silva, 2012; Oliveira, 2016). O Vocabulário Ortográfico converge para uma possibilidade futura de criar um dicionário geral da língua portuguesa que contemple as modalidades nacionais no plano 
vocabular. Conforme salientado pelo linguista Alberto Faraco: "Esse vasto acervo poderá servir de base para a escrita de um novo dicionário geral da língua, o que será um passo fundamental [...]. Aos poucos vai se consolidando o conceito de língua pluricêntrica para o português." (IILP, 2017).

Além do papel desempenhado pela CPLP, a internacionalização vista como um processo de dimensão global também é pauta da agenda da política externa conduzida pelos governos do Brasil e de Portugal, o que configura uma faceta heterogênea da lusofonia, dado que são iniciativas que promovem a cisão da língua em português europeu e português brasileiro. Em sua maioria, as ações de difusão linguística no exterior são empreendidas por meio da diplomacia cultural. Acionamos o conceito de soft power, desenvolvido por Joseph Nye (2004), para exemplificar o uso de estratégias atrativas e sedutoras na condução de uma política externa voltada a promoção da cultura e da língua.

A aproximação cultural entre países é uma estratégia que não apenas promove a língua, mas também articula um quadro de política externa que possibilita estabelecer cooperação econômica, educacional e política. Desse modo, no cenário global contemporâneo, a diplomacia cultural transformou-se em prioridade para os governos na condução de uma política externa sem o uso de estratégias militares ou ostensivas (Madeira Filho, 2016). No jogo internacional, a promoção da língua portuguesa tem sido conduzida por Portugal e Brasil, sendo que as ações de cooperação educacional objetivam fortalecer laços econômicos, sociais e culturais.

No Brasil, até 2018, a cooperação educacional vinha sendo conduzida principalmente pelo Ministério das Relações Exteriores, em que o soft power brasileiro pode ser evidenciado meio do ensino da língua e da cultura brasileira (Brasil, DCE). Não pretendemos tratar exaustivamente do tema, mas a título de exemplificação, o Brasil conduz cerca de 29 Centros Culturais no exterior cuja missão é difundir a língua e a cultura brasileira. Além disso, existem Núcleos de Estudos brasileiros que funcionam como unidades complementares de ensino, situados em embaixadas ou vice-consulados. Em articulação do Ministério da Educação e do Ministério das Relações Exteriores, o programa de Leitorado (Qualificação de Docentes e ensino de Língua Portuguesa - PQLP/CAPES) oferta vagas para professores universitários brasileiros atuarem no departamento de ensino de língua portuguesa em instituições universitárias estrangeiras (Rede Brasil Cultural, 2018).

A certificação brasileira para o português como língua estrangeira exemplifica mais 
uma política linguística que visa a internacionalização. O Celpe-Bras - Certificado de Proficiência em Língua Portuguesa - é o exame brasileiro que atesta a proficiência em português como língua estrangeira, reconhecido oficialmente pelo governo brasileiro. A certificação é requisitada em diversas situações, dentre elas, a validação de diplomas de profissionais estrangeiros que pretendem trabalhar no país, o ingresso de estudantes em cursos universitários e a inscrição profissional em entidades como o Conselho Federal de Medicina.

A avalição da proficiência atestada pelo Celpe-Bras foi implementada em 1998. Curiosamente, ocorreu no mesmo ano em que Portugal criou seu sistema de certificação e avaliação do português como língua estrangeira. A prova é desenvolvida pelo Ministério da Educação e aplicada duas vezes ao ano em universidades brasileiras credenciadas. No exterior, a aplicação se realiza nos Centros Culturais brasileiros, com apoio do Ministério das Relações Exteriores (Rede Brasil Cultural, 2018).

Uma das políticas de cooperação educacional, atrelada ao Celpe-Bras, que promove a internacionalização da língua portuguesa é o Programa de Estudantes-Convênio de Graduação (PEC-G). O rascunho inicial se deu por meio do decreto 55.613 de 20 de janeiro de 1965, aos moldes de um convênio cultural que possibilitou unificar as condições de intercâmbio estudantil de estrangeiros em universidades brasileiras. O programa passou por diversas modificações protocolares, na atualidade, o decreto 7.948 de 12 março de 2013 rege o PEC-G, celebrado entre o Ministério das Relações Exteriores e o Ministério da Educação (Brasil, Decreto 7.948/2013).

Desde os anos 2000, os países africanos que mais enviaram estudantes de graduação foram Cabo-Verde, Guiné-Bissau, Angola, Moçambique, São Tomé e Príncipe (Brasil, Ministério das Relações Exteriores, 2018). Não obstante, mesmo tendo a língua portuguesa oficializada, observamos que uma das exigências para os estudantes participarem do PEC-G é apresentar o certificado Celpe-Bras, o que não englobava os candidatos oriundos dos 'países lusófonos', de acordo com o protocolo de 1998.

Porém, a partir de 2013, o Celpe-Bras se tornou uma exigência, inclusive, para candidatos oriundos de países lusófonos (Brasil, Ministério das Relações Exteriores, 2018). Tal mudança estratégica opera em reforçar a invenção de um português brasileiro em contraposição ao português falado nos países da CPLP, ao mesmo tempo, amplia o espaço de atuação do português e da cultura brasileira, vinculado a interesses econômicos, comerciais e geopolíticos. A política linguística imposta para os cidadãos da CPLP que pretendem aderir 
aos programas do PEC-G coloca o Brasil no "centro de uma lusofonia" em uma postura neocolonizadora (Diniz; Bizon, 2015; Severo, 2015).

Por sua vez, Portugal também tem conduzido ações para a internacionalização da língua portuguesa, sendo que o Ministério dos Negócios Estrangeiros assume essa função (Portugal, Negócios Estrangeiros, 2018). A língua portuguesa converteu-se em principal estratégia econômica e de cooperação internacional no século XXI. O interesse econômico pela língua portuguesa é uma política bem delineada pelo governo português, haja vista que o Ministério dos Negócios Estrangeiros lidera o projeto de difusão linguística, com a colaboração do Ministério da Cultura e do Ministério da Educação e Ciência. A materialização dos projetos ligados à promoção cultural e linguística é assegurada pelo Camões - Instituto da Cooperação e da Língua, I.P. (Camões, I. P.), órgão da administração pública, criado em 2012, sob tutela do MNE (Portugal, Decreto Lei 21/2012).

Constatamos que o Camões I.P. vem se configurando em uma rede bastante integrada de promoção externa da língua e cultura portuguesas, por meio da gestão de Centros Culturais, de Centros de Língua Portuguesa, de Cátedras de investigação, de bibliotecas físicas e virtuais, bem como a coordenação de departamentos de ensino de português em universidades estrangeiras (Camões, I.P. 2018). Atualmente, o Instituto Camões coordena 56 Centros de língua portuguesa, em 39 países. O programa de leitorado é uma das políticas voltadas para difusão da língua, com a criação de departamentos de língua portuguesa e envio de professores portugueses em instituições de ensino estrangeiras.

Assim como o governo brasileiro, Portugal desenvolveu o certificado de proficiência da língua portuguesa. Tal certificação é articulada em duas modalidades: Ensino Português no Estrangeiro (EPE) e Certificação Português Língua Estrangeira (PLE). A primeira, disponibiliza a certificação para alunos entre 8 a 18 anos, filhos de portugueses nascidos na diáspora, que estão cursando ensino regular fora de Portugal e querem/precisam comprovar proficiência na língua portuguesa. Esse exame é aplicado pelo Camões I.P., sob responsabilidade conjunta do Ministério dos Negócios Estrangeiros e do Ministério da Educação e Ciência (Portugal, Decreto-Lei 234/2012).

Por sua vez, a segunda modalidade de certificação de Português Língua Estrangeira - PLE - é desenvolvida pelo Centro de Avaliação de Português Língua Estrangeira (CAPLE), que desde 2015 funciona como uma unidade orgânica da Faculdade de Letras da Universidade de Lisboa. O CAPLE foi criado por meio de protocolo assinado em março de 1999 entre o 
Ministério dos Negócios Estrangeiros, o Instituto Camões, o Ministério da Educação e a Universidade de Lisboa (Association Of Language Tests in Europe, 2016).

A certificação de português como língua estrangeira é aplicada somente aos cidadãos estrangeiros que desejam comprovar proficiência linguística para diversas finalidades como estudo, trabalho, obtenção de nacionalidade portuguesa, entre outros (Camões I.P., 2018). Entretanto, para estudar em Portugal, candidatos provenientes dos países de língua portuguesa estão isentos de realizar o exame de proficiência em português, política divergente do Celpe-Bras, conforme discutido.

Após tratar de algumas ações voltadas para a internacionalização do português, constatamos que o projeto político da lusofonia não opera somente em um movimento unificador, pois, visto de uma perspectiva da globalização, incluiu os localismos e os universalismos, além das interações transnacionais, sociais e culturais (Santos, 2002). As políticas oficiais transnacionais da língua portuguesa protagonizadas pelo IILP e pela CPLP estão em embate com as políticas promovidas pelos Estados e com as práticas sociais e linguísticas locais.

\section{Palavras finais}

Neste artigo problematizamos a ideia de internacionalização da língua portuguesa a partir de duas perspectivas: (i) a complexidade linguística e cultural de alguns países cuja língua oficial é a portuguesa - Angola, Moçambique, Cabo Verde, Guiné-Bissau e Timor Leste -; e (ii) as políticas levadas a cabo tanto pela CPLP como pelos governos brasileiro e português. Ao colocarmos em relação tais perspectivas, evidenciamos tensões e assimetrias, que tendem a favorecer as políticas institucionalizadas - CPLP e governos português e brasileiro - em detrimento das demandas e da realidade linguística local. Consideramos que tais tensões devem ser levadas em conta na análise do que significa "língua portuguesa" e de sua internacionalização, especialmente na relação entre políticas nacionais e políticas transnacionais. Embora reconheçamos um certo empenho da CPLP e dos governos brasileiro e português, especialmente por parte de intelectuais engajados com as questões linguísticas, no reconhecimento de um pluricentrismo da língua portuguesa, entendemos que tal empenho ainda se distancia dos contextos locais de uso da língua portuguesa na sua relação com as línguas nacionais de contextos multilíngues.

Assim, entendemos que uma dada concepção de educação - multilíngue, translíngue e 
heteroglóssica - deve ser capaz de definir o que conta como língua portuguesa e os seus lugares na formação intelectual e humana de uma sociedade. Deste modo, a escolarização em diálogos com concepções locais de educação e com apoio governamental - pode ajudar a reconhecer os significados que os sujeitos atribuem localmente às suas línguas. A internacionalização da língua portuguesa, a nosso ver, deve ser paralela e conjunta com uma política de reconhecimento e valorização das línguas locais, fazendo com que o multilinguismo não seja um problema e a oralidade não seja um obstáculo. Por fim, concordamos com Makoni e Meinhof (2006, p. 200) de que as "línguas africanas não necessariamente têm de ser padronizadas para ser ensináveis", o que significa que a representação gráfica de uma língua não deve ser condição para que ela possa ser praticada, valorizada e reconhecida.

\section{REFERÊNCIAS:}

ADRIANO, P. S. A crise normativa do português em Angola: clitização e regência verbal: que atitude normativa para o professor e revisor?. Luanda: Mayamba, 2015.

ASSOCIATION OF LANGUAGE TESTES IN EUROPE. (2016). Disponível em: http://www.alte.org/members/portuguese/index.php. Acesso em: 08 jan. 2019.

BAKHTIN, M. Questões de literatura e de estética. São Paulo: Unesp/Hucitec, 1988.

BALSALOBRE, S. R. G. Expressões de poder e de solidariedade em Moçambique e em Angola: observando a inter-relação entre gênero e formas de tratamento. RILP - Revista Internacional em Lingua Portuguesa, n. 32, p. 53-78, 2017.

BATORÉO, H. J.; CASADINHO, M. O Português - uma língua pluricêntrica: O Caso de Timor-Leste: De que forma os timorenses perspectivam e avaliam uma das suas línguas oficiais falada apenas por cinco por cento da população? Revista Portuguesa de Humanidades, Estudos Linguísticos, n. 13, v. 1. Braga: Universidade Católica Portuguesa de Braga, 2009, p. 63-79.

BATORÉO, H. J.; SILVA, A. S. Estudar o português como língua pluricêntrica no enquadramento da Linguística Cognitiva com foco nas variedades nacionais do PE e PB. In: TEIXEIRA E SILVA et al. III SIMELP: A formação de novas gerações de falantes de português no mundo. China, Macau: Universidade de Macau, 2012.

BAXTER, A. N. Portuguese as a pluricentric language. In: CLYNE, M. (Ed.). Pluricentric Languages: differing norms in different nations. Berlin, New York: Mountoun de Gruyter, 1992. p. 11-44.

BERNARDO, E. P. J. Norma e variação linguística: implicações no ensino da língua portuguesa em Angola. RILP - Revista Internacional em Lingua Portuguesa, n. 32, p. 37-52, 2017.

. Política linguística para o ensino bilíngue em Angola. 2018. Dissertação (Mestrado em Linguística) - Programa de Pós Graduação em Linguística, UFSC, Florianópolis. 177p.

BLOMMAERT, J. The sociolinguistics of globalization. Cambridge: Cambridge University Press, 2010. 
BRAGA, J. A. (Coord.). José Aparecido: o homem que cravou uma lança na lua. Lisboa: Trinova, 1999.

BRASIL. Decreto 7.948, 12 de março de 2013. Dispões sobre o Programa de EstudantesConvênio de Graduação - PEC-G. Disponível em: http://www2.camara.leg.br/legin/fed/decret/2013/decreto-7948-12-marco-2013-775489-public acaooriginal-139212-pe.html. Acesso em: 18 fev. 2019.

BRASIL, MINISTÉRIO DAS RELAÇÕES EXTERIORES. Divisão de Promoção da Língua Portuguesa. (2018). Disponível em: http://www.itamaraty.gov.br/pt-BR/diplomacia-cultural\#DPLP. Acesso em: 13 ago. 2018.

CABO VERDE. Instituto Nacional de Estatística - Estatísticas da Cultura, Desporto e Lazer em Cabo Verde, 2015. Disponível em http://ine.cv/estatisticas-por-tema/. Acesso em 06 de março de 2019.

CABO VERDE. Constituição Política da República de Cabo Verde. 1992. Disponível em http://portais.parlamento.cv/rppd/legislacao/cr.pdf. Acesso em 06 de março de 2019.

CAMÕ̃ES I.P. Investigar Língua e Cultura Portuguesa. (2018). Disponível em: http://www.instituto-camoes.pt/centros-de-lingua-portuguesa/root/lingua-e-ensino/centros-delingua. Acesso em: 08 abr. 2018.

CAMÕES I.P. Certificação EPE, Certificação PLE (2018). Disponível em: http://www.instituto-camoes.pt/activity/o-que-fazemos/aprender-portugues/certificacao-de-pr endizagens/certificacao- epe. Acesso em: 04 mai. 2018.

CPLP. Declaração Constitutiva (1996). Disponível em: https://www.cplp.org/id-3869.aspx. Acesso em: 18 fev. 2019.

CPLP. Estados-membros (2018). Disponível em: http://www.cplp.org/id-2597.aspx. Acesso em: 21 jan. 2018.

DIAS, C. “[...] é língua oficial de Timor-Leste, quer não quer nós tem falar": Reflexões sobre políticas e práticas linguísticas em Díli. 2015. Dissertação (Mestrado em Linguística) Programa de Pós-Graduação em Linguística, UFSC, Florianópolis. 125p.

DINIZ, L. R. A.; BIZON, A. C. C. Discursos sobre a relação Brasil/África "lusófona" em políticas linguísticas e de cooperação educacional. Línguas e Instrumentos linguísticos, n. 36, jul-dez, 2015. p. 125-165.

DISNEY, A. Portuguese expansion, 1400-1800: Encounters, negotiations, and interactions. In: F. Bethencourt; D. R. Curto (orgs.). Portuguese oceanic expansion, 1400-1800. New York: Cambidge University Press, 2007. p. 283-313.

FARDON, R.; FURNISS, G. African languages, development and the state. London/New York: Routeledge, 1993.

FERREIRA, J. P.; CORREIA, M.; ALMEIDA, G. B. (Orgs.). Vocabulário Ortográfico Comum da Língua Portuguesa. Praia: Instituto Internacional da Língua Portuguesa/ Comunidade dos Países de Língua Portuguesa, 2017.

FOUCAULT, M. Microfísica do poder. 3. ed. Trad. Roberto Machado. Rio de Janeiro: Paz e Terra, 2015.

GARCÍA, O. Bilingual Education in the 21st Century: A Global Perspective. Malden, MA and Oxford: Basil/Blackwell, 2009.

GARCÍA, O.; WEI Li. Translanguaging: Language, Bilingualism, and Educaticon. New York: Palgrave MacMillan, 2014.

GONÇALVEZ, P. Lusofonia em Moçambique: com ou sem glotofagia? 2012. Comunicação pessoal. Disponível

http://www.catedraportugues.uem.mz/lib/docs/lusofonia_em_mocamb

ique.pdf. Acesso em: 02 abr. 2016. 
GUINÉ-BISSAU, Terceiro Recenseamento Geral da População e Habitação (III RGPH). Instituto Nacional de Estatística, 2009. Disponível em http://www.stat-guinebissau.com/publicacao/caracteristicas_socio_cultural.pdf. Acesso em 06 março 2019.

IILP. Um vocabulário comum para uma língua pluricêntrica. 22 maio 2017. Disponível em: $<$ https://iilp.wordpress.com/2017/05/22/um-vocabulario-comum-para-uma-lingua-pluricentric a/>. Acesso em: 28 fev. 2018.

MADEIRA FILHO, A. P. Instituto de cultura como instrumento de diplomacia. Brasília: FUNAG, 2016.

MARCHUETA, M. R. A CPLP e seu enquadramento. Portugal: Ministério dos Negócios Estrangeiros, 2003.

MAKONI, S.; MEINHOF, U. Linguística Aplicada na África: desconstruindo a noção de língua. In: Moita Lopes, Paulo da. Por uma linguística aplicada indisciplinar. São Paulo: Parábola, 2006.

MIGUEL, M. H. Dinâmica da pronominalização no português de Luanda, Luanda: Mayamba, 2014.

MINGAS, A. Interferência do kimbundu no português falado em Lwanda. Luanda: Chá de Caxinde, 2007.

NGUNGA, A. Interferências de línguas moçambicanas em português falado em Moçambique. Revista Científica da Universidade Eduardo Mondlane. v. 1, n. 0, p. 7-20, 2012.

NYE, J. Jr. Soft Power: The Means to Success in World Politics. New York: Public Affairs, 2004.

NZAU, D. G. N. A língua portuguesa em Angola: um contributo para o estudo da sua nacionalização. 2011. 203 f. Tese (Doutorado) - Departamento de Letras, Universidade de Beira Interior, Covilhã, 2011.

OLIVEIRA, G. M. O Sistema de Normas e a evolução demolinguística da Língua Portuguesa. In: ORTIZ, M. L A.; GONÇALVEZ, L. (Orgs.). O Mundo do Português e o Português no Mundo afora: especificidades, implicações e ações. Campinas: Pontes, 2016. p. 25-43.

PENNYCOOK, A. Principled polycentrism and resourceful speakers. Journal of Asia Tefl, 11, n. 4, 2014, p.1-19.

PORTUGAL. Decreto-lei 21/2012. Disponível em: http://www.instituto-camoes.pt/images/legislacao/d121_2012_lo_camoes.pdf. Acesso em: 05 dez. 2018.

PORTUGAL, Decreto-Lei 234/2012. Disponível em: https://dre.pt/pesquisa/-/search/191541/details/maximized. Acesso em: 05 dez. 2018.

PORTUGAL, Ministério dos Negócios Estrangeiros. Política Externa, Língua e Cultura Portuguesas, $2018 . \quad$ Disponível em: https://www.portaldiplomatico.mne.gov.pt/politica-externa/lingua-e-cultura-portuguesas.

Acesso em: 03 mai. 2018.

REDE BRASIL CULTURAL. CELPE-Bras. Disponível em: $<$ http://redebrasilcultural.itamaraty.gov.br/menu-celpe-bras $>$. Acesso em: 31 out. 2018.

SITOE, S.; NHAMUENDE, P. Moçambicanismos: para um léxico de usos do português moçambicano. Maputo: Livraria Universitária, 2002.

SANTOS, B. de S. Os processos da globalização. In: SANTOS, Boaventura de Sousa (Org.). A Globalização e as Ciências Sociais. 2. ed. São Paulo: Cortez, 2002. p. 25-94.

SEVERO, C. G.; MAKONI, S. B. Políticas Linguísticas Brasil-África: Por uma perspectiva crítica. Florianópolis: Insular, 2015.

SEVERO, C. G. A açucarada Língua Portuguesa: Lusotropicalismo e Lusofonia no século XXI. Revista Brasileira de Linguística Aplicada, v. 15, p. 85-107, 2015. 
SILVA, A. S.; TORRES, A.; GONÇALVES, M. (Orgs.). Línguas Pluricêntricas. Variação Linguística e Dimensões Sociocognitivas. Braga: Aletheia, 2012.

TIMBANE, A. A. A variação linguística do português moçambicano: uma análise sociolinguística da variedade em uso. RILP - Revista Internacional em Língua Portuguesa, $\mathrm{n}$. 32, p. 17-36, 2017.

Recebido em 07/03/2019. Aceito em 31/08/2019. 